\title{
Dielectric Behavior of Nano Lead - Nano Copper oxides Polyvinyl Chloride (PVC) Composites
}

\author{
Yehia. M. Abbas ${ }^{1}$, Ahmed. M. El-Khatib ${ }^{2}$, Mohamed. S. Badawi ${ }^{2,}$, \\ Mahmoud. T. Alabsy' ${ }^{2}$, Osama. M. Hagag,"* \\ ${ }^{1}$ Department of Physics, Faculty of Science, Suez Canal University, Ismailia, Egypt. \\ ${ }^{2}$ Physics Department, Faculty of Science, Alexandria University, Alexandria, Egypt. \\ ${ }^{3}$ Physics Department, Faculty of Science, Port Said University, Port Said, Egypt. \\ Physics Department, Faculty of Science, Beirut Arab University \\ *Corresponding author: hagag82@yahoo.com
}

\begin{abstract}
The dielectric properties of pure PVC and pure PVC filled composites were performed to examine and characterize the structure of polymer composites. At room temperature the values of relative permittivity, loss factor, and ac conductivities were calculated as a function of frequency and it was found that incorporation of both micro and nano $\mathrm{PbO}$ and $\mathrm{CuO}$ with various wt\% to the polymer matrix resulted in enhanced dielectric properties. The electrical response of polymer matrix micro- or nanocomposites show their conductivity and dielectric behavior. So the principal electrical character of polymers is insulating because of their very low concentration of free charge carriers, polymer nanocomposites (also called nanodielectrics) appear to be dielectrics or in other words, materials that will be polarized by applying an external electric field. Nano composites are closely associated with the development of cutting-edge electronic and optoelectronic devices. The nanoscale has been reached on the dimensional scale of electronic devices. The usefulness of polymer/inorganic molecule nanocomposites varies greatly, with various potential applications as well as different types of nanocomposites.
\end{abstract}

\section{Keywords}

Polyvinyl chloride, nano lead oxide, nano copper oxide, dielectric property.

\section{INTRODUCTION}

Later on, rapid correspondence network applications, unsuitable dielectric properties, and lacking warm solidness are the principal boundaries to the use of polymer materials. Among the enormous number of prerequisites that low dielectric polymer materials should meet, the main necessity is warm solidness. Most high-temperature polymers have been exhorted as low-dielectric materials for cutting-edge rapid correspondence gear. To guarantee the typical activity of electronic gear, it is normally important to deal with the metal interconnection wires at a temperature higher than $400 \pm 50^{\circ} \mathrm{C}$ for a few hours [1].

Union of semiconducting nanostructures and profoundly investigating their properties to discover their reasonableness for a wide assortment of utilizations is one of the quickest developing regions in material science and designing [2]. 
Solution casting was used to make thin films of a poly(vinyl chloride)-poly(methyl methacrylate) (PMMA) blend with lithium triflate $\left(\mathrm{LiCF}_{3} \mathrm{SO}_{3}\right)$ salt and dibutyl phthalate (DBP) as a plasticizer. These films were tested for conductivity and dielectric properties as a function of frequency and temperature. The addition of DBP increased the ionic conductivity significantly. The conductivity-temperature plots were discovered to be Arrhenius. The mentality of the samples was investigated using their dielectric permittivity $\dot{\varepsilon}(\mathrm{eV})$, dissipation factor $(\tan \delta$ ), and electric modulus (MV)[3]. These properties vigorously rely upon the size, shape, arrangement, and planning conditions. This paper reports the dielectric investigations of $\mathrm{CuO} / \mathrm{PVC}$ and $\mathrm{PbO} / \mathrm{PVC}$ nanocomposites which is an innovatively significant material. A huge expansion in dielectric consistency is seen in the nanocomposite with a lessening in recurrence than that in regular materials because of various polarization systems[2].

The addition of $\mathrm{ZnO}$ NPs to PVC resulted in a major improvement in breakdown strength. The breakdown strength values for PVC/0.14 vol percent $\mathrm{ZnO}$ were up to 45 percent higher than the pristine PVC sample. The effect of NP dispersibility due to the additional procedures used on DC dielectric strength was investigated and verified using FE-SEM. The real part of permittivity $\left(\varepsilon^{\prime}\right)$ was found to be dependent on filler concentration, confirming the DC dielectric strength findings [4].

This research aims to improve the dielectric properties of polyvinyl chloride by manufacturing sheets of polyvinyl chloride injected with metal oxides such as lead oxide and copper oxide at different concentrations and then making comparisons to reach the best concentrations as well as injecting polyvinyl chloride with lead oxide and copper oxide[5] in the nanoscale to compare with the best previous concentrations to prove the effectiveness of nanotechnology in improving the dielectric properties [6],[7].

\section{MATERIALS AND METHODS}

\subsection{Preparation of $\mathrm{PbO}$ nanoparticles}

$\mathrm{PbO}$ nanoparticles were synthesized chemically [8] according to the following steps:

1. Adding $150 \mathrm{ml}$ of distilled water to $114 \mathrm{~g}$ of $\mathrm{NaOH}$ then mixed.

2. Add $180 \mathrm{ml}$ of distilled water with $68.1 \mathrm{~g}$ of lead acetate and warm at $90{ }^{\circ} \mathrm{C}$ in an oven.

3. Mix the previous $\mathrm{NaOH}$ solution with lead acetate solution until the red color is obtained.

4. Filtrate the precipitate and dry it at $100{ }^{\circ} \mathrm{C}$ for 8 hours.

5. The dried precipitate has been lightly pounded by an agate pestle (The Mortar Grinder RM 200) and mortar to obtain a yellow precipitate.

\subsection{Preparation of $\mathrm{CuO}$ nanoparticles}

$\mathrm{CuO}$ nanoparticles were synthesized chemically [9] according to the following steps:

1. Adding $15 \mathrm{~g}$ ascorbic acid, $2 \mathrm{~g} \mathrm{CuSO} 4$ to $100,50 \mathrm{ml}$ hot water respectively.

2. Then mix them for about 3 minutes and put in an oven at $80{ }^{\circ} \mathrm{C}$ for 12 hours.

3. The resulting product was removed and lightly pounded by an agate pestle (The Mortar Grinder RM 200) and mortar to obtain a black precipitate.

\subsection{Synthesis of PVC composites}

Polyvinyl Chloride (PVC) is a generally utilized plastic material that is one of the most valuable items for the substance business. All-inclusive over half of the industrial facility PVC is utilized in development as a development material since it is modest and simple to introduce. Lately, polyvinyl chloride has supplanted numerous development materials in numerous zones despite worries about the effect of polyvinyl chloride on the earth and human wellbeing [1]. PVC loaded with different $\mathrm{wt} \%$ filler $(\mathrm{PbO})$ either bulk or nano by weight were fabricating using a pressure forming system. Prepared according to the following steps[8]:

1. Preparing the different mixtures from the PVC powder and the filler.

2. The mixture as a powder was placed slowly in the pressure forming system to be compressed by two roll mixers at $180^{\circ} \mathrm{C}$ for 10 minutes at a speed of $40 \mathrm{rpm}$ to produce a homogeneous soft sample. 
3. Then the soft sample was poured into a stainless mold with dimensions $40 \times 40 \mathrm{~cm}^{2}$ and $0.3 \mathrm{~cm}$ thickness.

4. Using a laser beam the sheet was cut into discs with a diameter of $8.4 \mathrm{~cm}$ for studying the attenuation of gamma rays.

\subsection{Structural characterization}

A scanning electron microscope (SEM) (JSM-6010LV, JEOL) was employed to observe the micrographs and the cross-section morphologies of the prepared PVC composites filled with micro and nano $\mathrm{PbO} / \mathrm{CuO}$ particles. The samples were coated with an ultrathin gold coating using a low-vacuum sputtering coating system to prepare them for SEM observation. (JEOL-JFC-1100E). The SEM micrographs were taken at a magnification of one order of magnitude. 10,000x at $20 \mathrm{kV}$. Moreover, the distribution of the $\mathrm{PbO}$ and $\mathrm{CuO}$ nanoparticles in the PVC matrix was also analyzed by employing the field emission transmission electron microscope (FE-TEM) (JEM 2100F, JEOL, Japan) at $200 \mathrm{kV}$.

\subsection{Dielectric measurments}

The dielectric properties of each tested sample are measured by using two electrodes technique configurated with an impedance LCR meter (HIOKI IM 3536, Japan) with the computer interface to facilitate automatic scanning and data recording as shown in Figure (1). The measurements were carried out in a frequency range from $42 \mathrm{~Hz}$ up to $8 \mathrm{MHz}$ for 406 frequency points, at room temperature. The measured parameters in this work are relative permittivity $(\dot{\varepsilon})$, loss tangent or loss factor $(\tan \delta)$, and ac conductivity $\left(\sigma_{\text {ac }}\right)$.

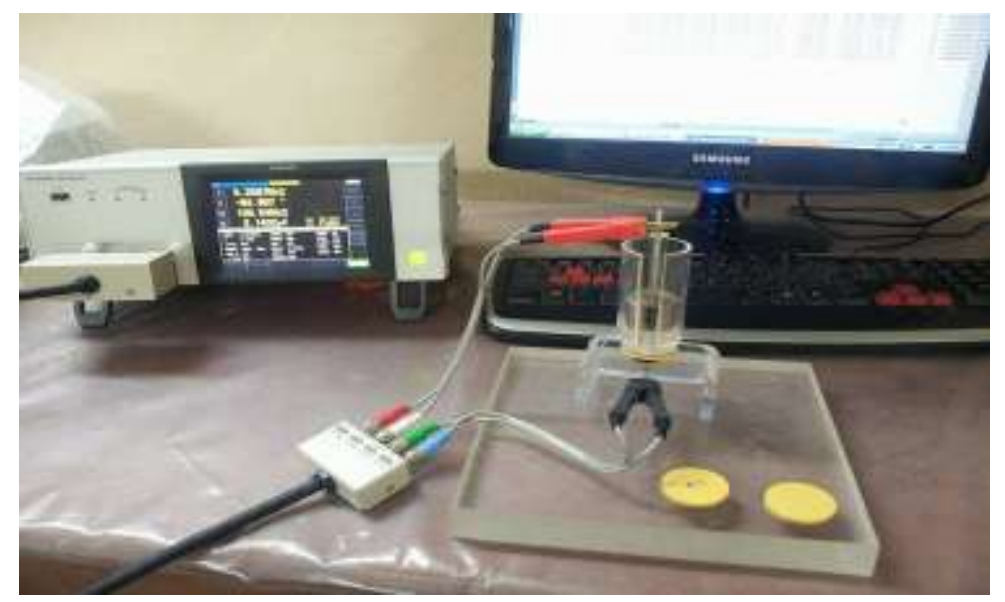

Figure 1. HIOKI IM 3536 LCR METER

The specimens for dielectric measurements were made in the form of circular disks (three samples for each category to check reproducibility) with $0.2 \mathrm{~cm}$ in thickness and $3 \mathrm{~cm}$ in diameter and these circular disks were cut from the previously prepared sheets. For comparative tests, three disks of $\mathrm{PbO}$ and $\mathrm{CuO} \mathrm{NPs}$ and bulk $\mathrm{PbO}$ and $\mathrm{CuO}$ were prepared with thickness of $0.5 \mathrm{~cm}$ and diameter of $1 \mathrm{~cm}$. The disks were obtained by pressing certain amount of either bulk or nano $\mathrm{PbO}$ and $\mathrm{CuO}$ powders under 200 bar for 45 seconds at room temperature by using GRIMCO PRESSES 65 first Avenue, PATERSON, N.J07514. 50 tons compression press hydraulic model 50-1818-D. The spiecmen was laid out between two parallel circular plane silver electrodes of diameter $0.6 \mathrm{~cm}$ to form a plane-plane capacitor and fixed at constant pressure by two insulated clipses to provide electrical connections. The output signal from a wire braid mounted on the outer surface of the insulation was measured after a $0.1 \mathrm{~V}$ input voltage was applied to the central metal conductor of the coaxial cable samples.. When electrical field passes between the plates, it will induce a charge density. Then the potential between the plates is measured and used to calculate capacitance $\mathrm{C}$ and conductance $\mathrm{G}$ from Eq. 1 and Eq. 2

$$
\begin{aligned}
& G=\sigma \frac{A}{d} \\
& C=\varepsilon_{0} \varepsilon_{r} \frac{A}{d}
\end{aligned}
$$


Where, $A$ is the surface area of parallel plate capacitor, $d$ is the separation, $\sigma$ is the conductivity, $\varepsilon_{\mathrm{r}}$ the relative permittivity of the tested sample, and $\varepsilon_{0}$ is the relative permittivity of free space $\left(8.85 \times 10^{-12} \mathrm{~F} / \mathrm{m}\right)$ [10]. The capacitance $(C)$, the conductance $(G)$, the loss factor $(D)$, and the impedance $(Z)$ were measured at each frequency and data recorded for each sample. Three parallel measurements were performed the average value was used for each sample.

$\mathrm{G}$ and $\mathrm{C}$ represent the conductance and capacitive properties of the sample. The values of parallel resistance $\left(\mathrm{R}_{\mathrm{p}}\right)$ and capacitance $\left(\mathrm{C}_{\mathrm{p}}\right)$ which mostly reflected the leakage current of the voltage amplifying circuit of the impedance analyzers and stray capacitance in the circuit are determined from $42 \mathrm{~Hz}$ to $8 \mathrm{MHz}$ by measuring the open circuit impedance whereas the capacitor chamber was empty (and thus $\mathrm{R}, \mathrm{C} \rightarrow \infty$ ). The values of the series resistance $\left(\mathrm{R}_{\mathrm{s}}\right)$ and inductance $\left(\mathrm{L}_{\mathrm{s}}\right)$ of the leads connected to the two electrodes are determined from $42 \mathrm{~Hz}$ to $8 \mathrm{MHz}$ by measuring the short circuit impedance when the capacitor electrodes are shorted together (and thus $\mathrm{R}, \mathrm{C} \rightarrow 0$ ). Figure (2) represents Circuit model of capacitor cell measurements [11].

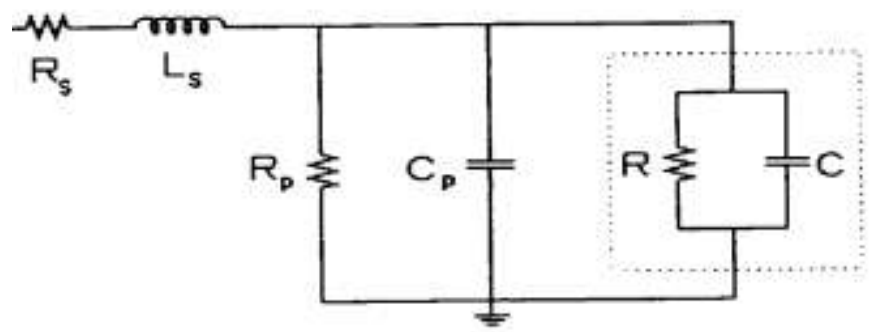

Figure 2. Circuit model of capacitor cell measurements

The values of the relative permittivity $(\dot{\varepsilon})$ of the tested samples for each frequency are obtained from the recoreded data of capacitances (C) using Eq. 3.

$$
\varepsilon^{\prime}=\frac{C d}{\varepsilon_{0} A}
$$

The values of the dielectric loss $\left(\varepsilon^{\prime \prime}\right)$, the conductivity $(\sigma)$, and loss tangent ( $\tan \delta$ ) of the tested samples for each frequency are obtained from the recorded data of G, and D using the following equations:

$$
\begin{aligned}
& \tan (\delta)=\frac{1}{2 \pi f R C} \\
& \varepsilon^{\prime \prime}=\varepsilon^{\prime} \tan (\delta) \\
& \sigma=2 \pi f \varepsilon^{\prime \prime} \varepsilon_{0}
\end{aligned}
$$

Where, $\dot{\varepsilon}$ and $\varepsilon^{\prime \prime}$ are the relative permittivity (or dielectric constant) and dielectric loss, respectively, $f$ is the applied frequency in Hertz, $\mathrm{R}$ and $\mathrm{C}$ are the measured resistance and capacitance values of the whole specimen, A is the cross-sectional area of the measured surface, and $\mathrm{d}$ is the thickness of the specimen in the direction of measurement [12]. During the test, the data were recorded across the entire frequency spectrum of measurement from $42 \mathrm{~Hz}$ to $8 \mathrm{MHz}$ and after calculating the values of the dielectric constant, the dielectric loss, the conductivity, and loss factor, a graph between each of these parameters (on the Y-axis) against log frequency (on X-axis) was plotted to investigate the dielectric property's dependence upon frequency.

\section{Structural analysis}

\section{RESULTS AND DISCUSSION}

\section{Scanning electron microscopy (SEM)}

The SEM micrographs of pure PVC and PVC composites filled with $40 \mathrm{wt} \%$ micro $\mathrm{CuO}, 40 \mathrm{wt} \%$ nano $\mathrm{CuO}, 40$ wt.\% micro $\mathrm{PbO}$, and 40 wt.\% nano $\mathrm{PbO}$ are displayed in Figure 3. Figure 3 demonstrates that there is a clear variation between the morphology of pure PVC (Figure 3) and $\mathrm{CuO} / \mathrm{PVC}$ and $\mathrm{PbO} / \mathrm{PVC}$ 
composites (Figure 3b-e). From Figure 2b-e, the SEM micrographs of micro-and nano- CuO/PVC and $\mathrm{PbO} / \mathrm{PVC}$ composites at $40 \mathrm{wt} \%$ are compared. It is clear that, in the case of nanocomposites, the nanoparticles are dispersed uniformly and well embedded in the PVC matrix which provides an interlocking structure for shielding. Whereas, in the case of micro composites, bulky particles are not well covered with the PVC matrix and some of them are peeled off from the matrix which acts as voids for shielding.
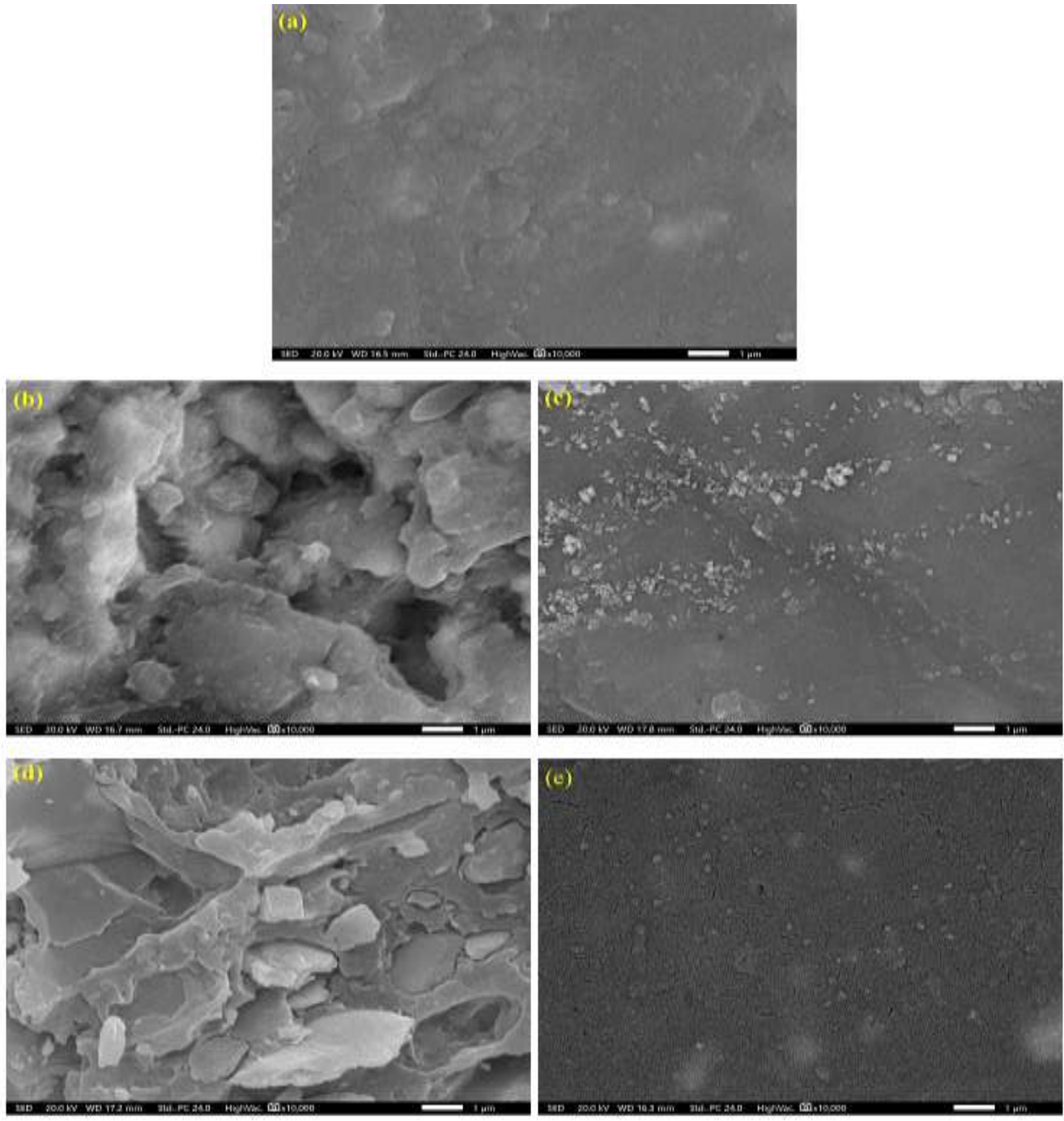

Figure 3. SEM micrographs of (a) Pure PVC, (b) $40 \mathrm{wt} \% \%$ micro CuO /PVC, (c) 40 wt. $\%$ nano CuO /PVC, (d) 40 wt. $\%$ micro $\mathrm{PbO} / \mathrm{PVC}$, and (e) $40 \mathrm{wt} \%$ nano $\mathrm{PbO} / \mathrm{PVC}$ composites.

\section{Field-emission transmission electron microscopy (FE-TEM)}

The FE-TEM micrographs of the PVC composites filled with $20 \mathrm{wt} \%$ nano $\mathrm{PbO}$ and $20 \mathrm{wt} \%$ nano $\mathrm{CuO}$ is shown in Figure $4 \mathrm{a}$ and Figure $4 \mathrm{~b}$ respectively. From Figure $4 \mathrm{a}$, it is noticed that $\mathrm{PbO}$ nanoparticles have a spherical shape with a particle size around $30 \mathrm{~nm}$. Besides, Figure $4 \mathrm{~b}$ shows the presence of $\mathrm{CuO}$ nanoparticles with an average particle size of around $15 \mathrm{~nm}$. 


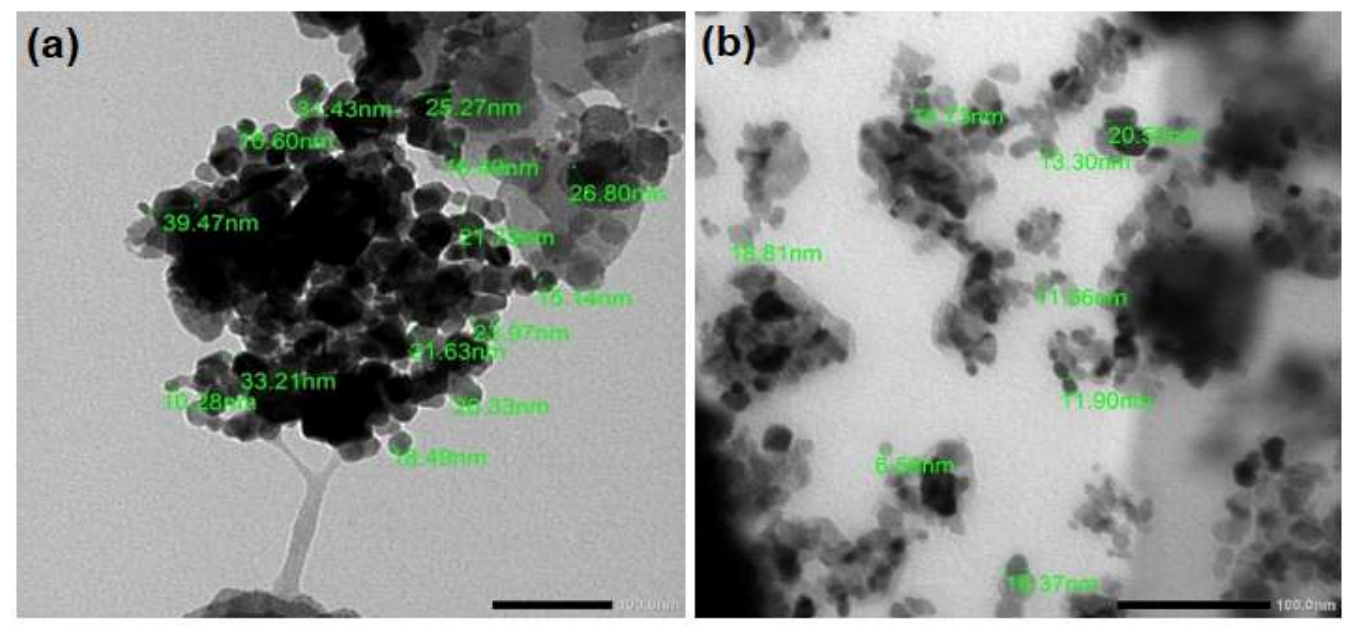

Figure 4. FE-TEM micrographs of (a) $20 \mathrm{wt} . \%$ nano $\mathrm{PbO} / \mathrm{PVC}$, and (b) 20 wt. $\%$ nano $\mathrm{CuO} / \mathrm{PVC}$ composites.

\section{Dielectric properties and AC conductivity}

Studying the dielectric properties of pure PVC, and pure PVC filled composites are considered a convenient and sensitive method to examine and characterize the structure of polymer composites. The most important parameters measured in this study are relative permittivity $(\dot{\varepsilon})$, loss tangent $\tan \delta$ (also called loss factor or dissipation factor), and ac conductivity $(\sigma)$. The samples under investigation were examined with respect to frequency and composition.

The dielectric constant, also known as relative permittivity, is a parameter that indicates the relative charge storage capacity of dielectrics in the presence of an applied electric field. The relative permittivity is one of the basic electrical properties of solids and it can be calculated from the electrical capacitance $(\mathrm{Cp})$ for bulk ( $\mathrm{PbO}$ and $\mathrm{CuO}),(\mathrm{PbO}$ and $\mathrm{CuO}) \mathrm{NPs}$, pure $\mathrm{PVC}$, pure $\mathrm{PVC}$ /bulk $\mathrm{PbO}$, pure $\mathrm{PVC} /$ bulk $\mathrm{CuO}$ composites, and $\mathrm{PVC} / \mathrm{PbO}, \mathrm{PVC} / \mathrm{CuO}$ nanocomposites at room temperature and frequency dependence of relative permittivity $(\dot{\varepsilon})$ can be represented graphically in Figure (5). As a result of interfacial polarisation alone, the dielectric constant approaches a constant value with increasing frequency at high frequencies. This may be explained by dipoles being able to align themselves and lead to complete polarisation at low frequencies, but the field variation at high frequencies is too fast for the dipoles to cope with. In contrast, The real part of the dielectric constant decreases with increasing frequency at low frequencies, which may be due to the contribution of several polarisation components such as deformational polarisation and relaxation [13].

The relative permittivity of the composites under investigation increases with the increasing the wt $\%$ and the maximum permittivity recorded for $40 \mathrm{wt} \%$ composition. Thus, the relative permittivity of Pure PVC is enhanced by increasing fillers loading but, the pure PVC still has the predominate effect[14] This is can be explained as follows; insulating compounds do not have an interface for charge storage and therefore, their dielectric constant is small. With the addition of conductive particles especially nanoparticles, the interface between the compounds and conductive particles increases dramatically, leading to a higher relative permittivity for the composites[15]. 


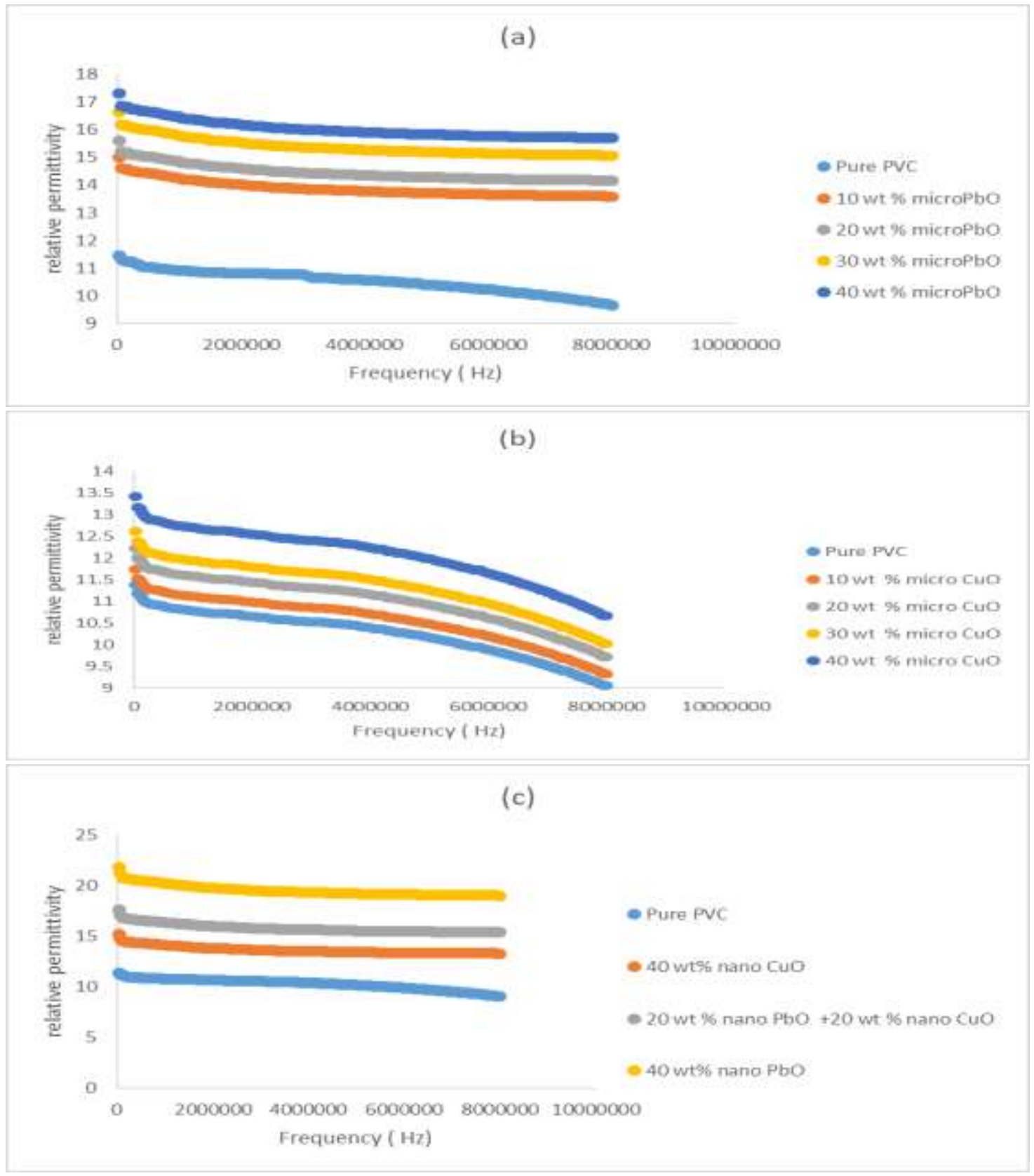

Figure 5. Frequency dependence of the relative permittivity ( $\dot{\varepsilon}$ ) of (a) micro $\mathrm{PbO} / \mathrm{PVC}$, (b) micro $\mathrm{CuO} / \mathrm{PVC}$ composites, and (c) 40 wt.\% nano CuO/PVC, 40 wt.\% nano PbO/PVC, and (20 wt.\% nano $\mathrm{CuO}$ +20 wt. \% nano $\mathrm{PbO}) / \mathrm{PVC}$ composites.

The loss factor is a measure of the loss of energy in a dielectric material through conduction, and it is preferred to be smaller for insulation materials. Figure (6) displays the loss factor against frequency for micro $\mathrm{PbO}$ and $\mathrm{CuO}, \mathrm{PbO}$ and $\mathrm{CuO}$ NPs, pure $\mathrm{PVC}$, pure $\mathrm{PVC} /$ micro $\mathrm{PbO}$ composites, and $\mathrm{PVC} / \mathrm{PbO}$, $\mathrm{PVC} / \mathrm{CuO}$ nanocomposites at room temperature. It can be seen from Figure (6) that, the loss factor curve of pure $\mathrm{PVC}$, micro $\mathrm{PbO}, \mathrm{CuO}$, and $\mathrm{PbO}, \mathrm{CuO}$ NPs possess the same behavior which involves decreases for the loss factor with an increase in the frequency. As the frequency increased, the dipole polarization effects reduced, and the values of the loss factor declined accordingly. 


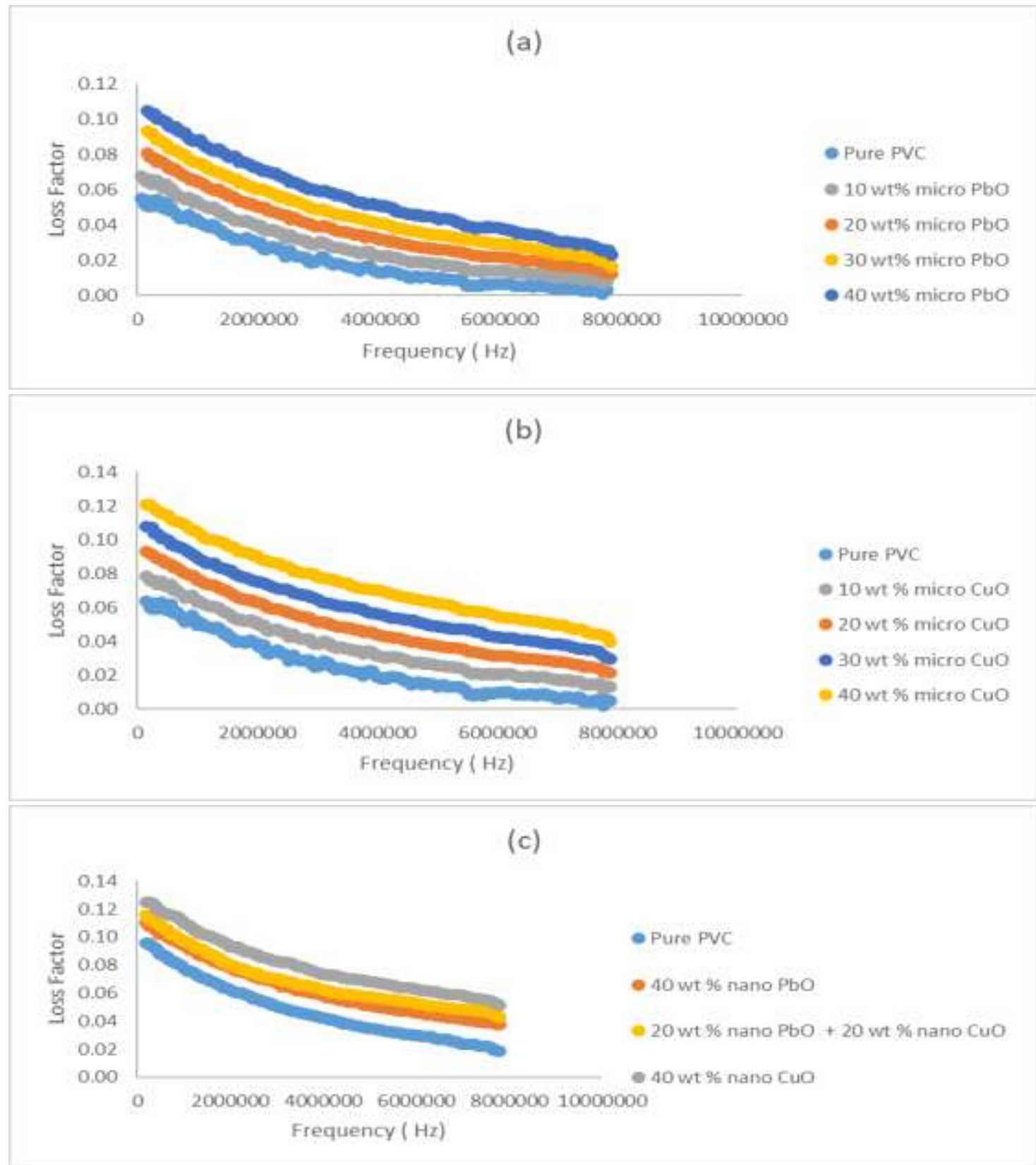

Figure 6. Frequency dependence of the loss factor $(\tan \delta$ ) of (a) micro $\mathrm{PbO} / \mathrm{PVC}$, (b) micro $\mathrm{CuO} / \mathrm{PVC}$ composites, and (c) 40 wt.\% nano CuO/PVC, 40 wt.\% nano PbO/PVC, and (20 wt.\% nano $\mathrm{CuO}+20$ wt. $\%$ nano $\mathrm{PbO} / \mathrm{PVC}$ composites.

Electrical conductivity is a physical quantity that characterizes how easily electric charge can flow through materials. The ac conductivity of micro $\mathrm{PbO}$ and $\mathrm{CuO}, \mathrm{PbO}$ and $\mathrm{CuO}$ NPs, pure $\mathrm{PVC}$, pure $\mathrm{PVC} / \mathrm{micro} \mathrm{PbO}$ composites, and $\mathrm{PVC} / \mathrm{PbO}, \mathrm{PVC} / \mathrm{CuO}$ nanocomposites as a function of frequency at room temperature are plotted in Figure (7) which displays an increase in the ac conductivity where the frequency-dependent ac conductivity mainly comes from the effects of polarization between clusters and the anomalous diffusion within the cluster. Also, the curve of $\mathrm{PbO}$ and $\mathrm{CuO}$ NPs shows higher values of ac conductivity at highfrequency ranges. This is attributed to the large surface area to volume ratio as well as the small size of the nanoparticles 13]. 

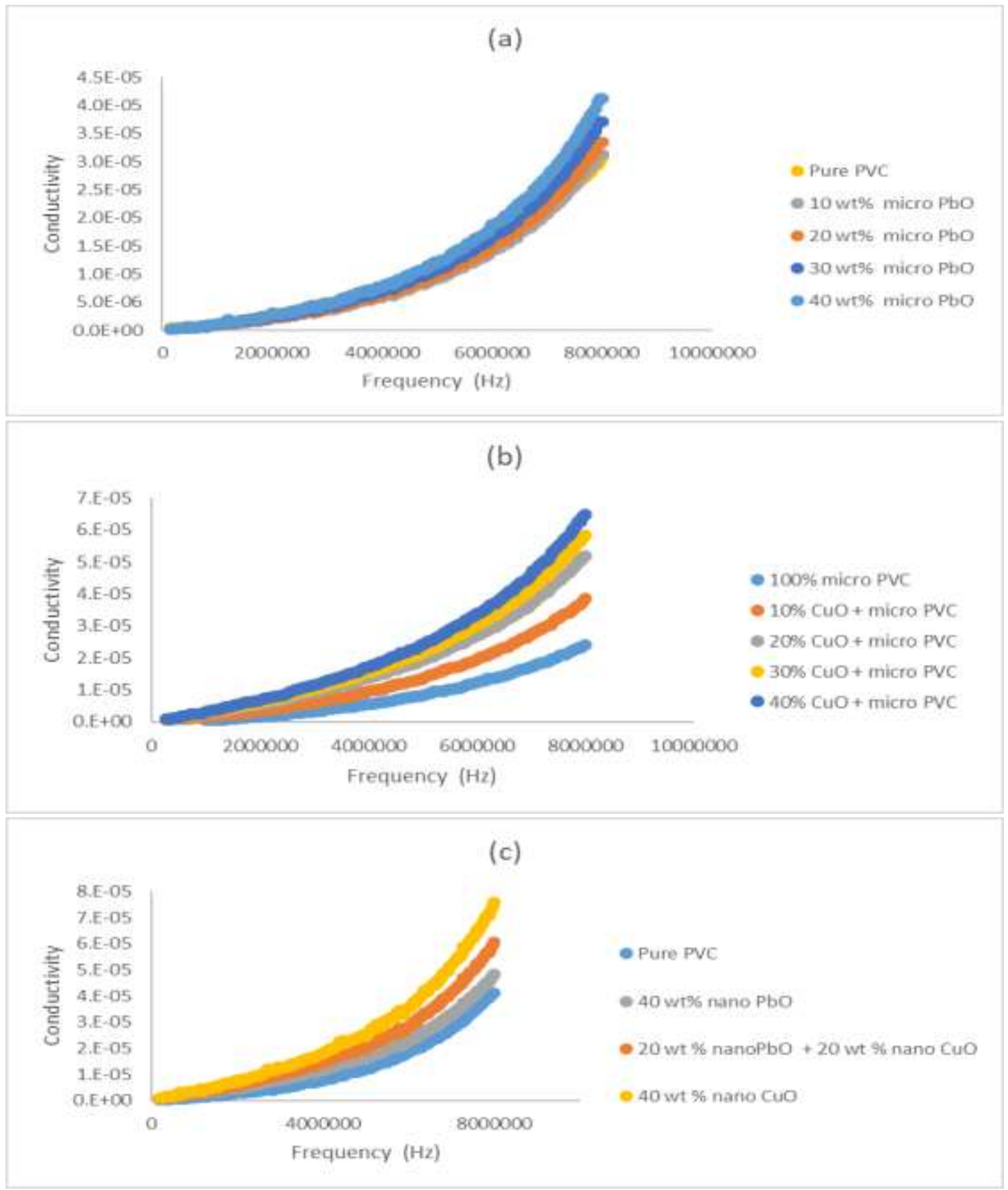

Figure 7. Frequency dependence of the ac conductivity of (a) micro $\mathrm{PbO} / \mathrm{PVC}$, (b) micro $\mathrm{CuO} / \mathrm{PVC}$ composites, and (c) 40 wt.\% nano $\mathrm{CuO} / \mathrm{PVC}, 40 \mathrm{wt} . \%$ nano $\mathrm{PbO} / \mathrm{PVC}$, and $(20 \mathrm{wt} . \%$ nano $\mathrm{CuO}+20 \mathrm{wt} . \%$ nano $\mathrm{PbO} / \mathrm{PVC}$ composites.

\section{CONCLUSION}

Firstly, the dielectric properties of pure PVC and PVC filled composites were performed. The values of relative permittivity, loss factor, and ac conductivities were measured as a function of frequency at room temperature and it was found that the dielectric properties of assembled composites as a function of frequency and filler weight fraction as compared to pure $\mathrm{PVC}$, both of the $\mathrm{PbO} / \mathrm{PVC}$ and $\mathrm{CuO} / \mathrm{PVC}$ composites showed improved dielectric properties, suggesting that these composites could be useful in the electrical insulation industry. These investigations also aid in distinguishing between localized and free band conduction mechanisms within a material. The dielectric values of the synthesized nanocomposites show major enhancement in the low-frequency region due to several polarisation mechanisms, according to dielectric studies. Conductivity measurements revealed a linear increase in conductivity with frequency due to a tunnelling form of conduction mechanism originating from thermally induced localized states. 


\section{REFERENCES}

[1] Wang, L., Liu, C., Shen, S., Xu, M., Liu, X. "Low dielectric constant polymers for high speed communication network” Adv. Ind. Eng. Polym. Res., vol. 3, pp.138-148. 2020.

[2] Abraham, N., Aseena, S. "Dielectric studies of $\mathrm{CuO}-\mathrm{ZnO}$ heterojunction nanocomposites synthesized by co-precipitation method Mater" Today Proc., 2021.

[3] Ramesh, S., Yahiya, A. H., Arof, A. K. "Dielectric behaviour of PVC-based polymer electrolytes" Solid State Ionics, vol. 152-153, pp. 291-294. 2002.

[4] Mansour, S. A., Elsad, R. A., Izzularab, M. A. "Dielectric properties enhancement of PVC nanodielectrics based on synthesized ZnO nanoparticles" J Polym Res, vol. 23, pp. 85. 2016.

[5] Khalil, A. "Relative biophysical effects on rat's bone as result of high energy photons and magnetic fields exposures" Arab J. Nucl. Sci. Appl., 2019.

[6] El-Kaliuoby, M. I., Khalil, A. M., El-Khatib, A. M., Shehata, N. "Antibacterial synergism of electrospun nanofiber mats functioned with silver nanoparticles and pulsed electromagnetic waves" Polymers (Basel), vol. 13, pp. 1-15. 2021.

[7] Hamid, A., Khan, M., Hayat, A., Raza, J., Zada, A., Ullah, A., Raziq, F., Li, T., Hussain, F. "Probing the physio-chemical appraisal of green synthesized $\mathrm{PbO}$ nanoparticles in PbO-PVC nanocomposite polymer membranes Spectrochim" Acta - Part A Mol. Biomol. Spectrosc., pp. 235. 2020.

[8] Abbas, Y. M., El-khatib, A. M., Badawi, M. S., Alabsy, M. T. "Gamma Attenuation Through Nano Lead - Nano Copper PVC Composites Preparation of PbO nanoparticles" 2021.

[9] El-Khatib, A. M., Salem, B. A., Badawi, M. S., Gouda, M. M., Thabet, A. A., Abbas, M. I. "FullEnergy peak efficiency of an $\mathrm{NaI}(\mathrm{Tl})$ detector with coincidence summing correction showing the effect of the source-to-detector distance" Chinese J. Phys., vol. 55, pp. 478-489. 2017.

[10] Sierpowska, J. "Electrical and dielectric characterization of trabecular bone quality" (University of Kuopio). 2007.

[11] Webster, J. R. "Thin film polymer dielectrics for high-voltage applications under severe environments" 1998.

[12] Gouda, O. E., Mahmoud, S. F., El-Gendy, A. A., Haiba, A. S. "Improving the dielectric properties of high density polyethylene by incorporating clay-nanofiller" World J. Eng. Technol., vol. 2, pp. 289. 2014.

[13] Sepet, H., Tarakcioglu, N., Misra, R. D. "Investigation of mechanical, thermal and surface properties of nanoclay/HDPE nanocomposites produced industrially by melt mixing approach" J. Compos. Mater., vol. 50, pp. 3105-3116. 2016.

[14] Ahangaran, F., Hassanzadeh, A., Nouri, S., Esmaeely, N. R. "Investigation of thermal and dielectric properties of $\mathrm{Fe} 3 \mathrm{O} 4 /$ high-density polyethylene nanocomposites" J. Compos. Mater., vol. 51, pp. 3923-3929. 2017.

[15] Deng, Y., Li, N., Wang, Y., Zhang, Z., Dang, Y., Liang, J. "Enhanced dielectric properties of low density polyethylene with bismuth sulfide used as inorganic filler Mater" Lett., vol. 64, pp. 528530. 2010.

[16] Xiliang, C. "Electrical and optical properties of MWNTs / HDPE composites in Terahertz region" Nuclear Science and Techniques, vol. 23, pp. 156-162. 2012. 